ORIGINAL PAPER

\title{
SUPPRESSION AND STIMULATION OF IMMUNOGLOBULIN SYNTHESIS BY AGENTS PRESENT IN RHEUMATOID SYNOVIAL EFFUSIONS
}

\author{
BY M. ROSENTHAL \\ Rheumatologische Universitätsklinik, Felix Platter-Spital, Burgfelderstrasse 101, CH-4055 \\ Basel, Switzerland \\ SUMMARY \\ Synovial effusions from 14 patients with rheumatoid arthritis cantain factors capable of enhan- \\ cing and suppressing the production of immunoglobulin when added to normal peripheral \\ lymphocyte cultures in vitro. Utilizing a radioactive immune coprecipitation tochnique it could be \\ demonstrated that enhancement was observed upon addition of relatively small amounts of \\ synovial fluid, while addition of higher amounts resulted in suppression of immunoglobulin \\ synthesis. Nine of ten non-rheumatoid joint effusions showed neither enhancing nor suppressing \\ activities. The possible relationship of these events to lymphokine production in the joint is \\ discussed.
}

THE participation of immune mechanisms in the pathogenesis of rheumatoid arthritis (RA) is well established (Pekin et al., 1964; Smiley et al., 1968; Winchester et al., 1969; Rodman et al., 1967). Recently, we described the presence in rheumatoid synovial effusions of enhancing factors capable of stimulating immunoglobulin synthesis in peripheral-blood lymphocyte cultures in vitro (Rosenthal et al., 1976). The factors described are a low-molecular factor which elutes from an Agarose A 5m column with serum albumin, presumably a lymphokine, and a high-molecular factor, which elutes from such a column with an IgM marker, presumably an immune complex. The lowmolecular factor is non-specific and stimulates immunoglobulin synthesis in both rheumatoid and normal lymphocyte cultures. The high-molecular factor showed specificity in its exclusive stimulation of rheumatoid cells. Recently, evidence has accumulated that in the collaboration between T-B cells and macrophages, $\mathrm{T}$ cells not only have an enhancing effect on antibody response, but also have a suppressive effect on antibody formation (Baker et al., 1973; Hardin et al., 1973; Dutton, 1973; Herzenberg et al., 1973; Sjoberg, 1972). The experiments presented here were designed to investigate the possibility that not only a B-cell enhancing function, but also B-cell suppression function is mediated by soluble factors. Such B-cell inhibitory factors may be produced in vivo by the inflamed synovium in rheumatoid arthritis and be present in the synovial effusion.

\section{MATERIALS AND METHODS}

Knee-joint effusions from 14 patients with classical or definite rheumatoid arthritis (RA) as defined by the A.R.A. criteria (Ropes et al., 1959) and from 10 non-rheumatoid patients were obtained. The non-rheumatoid patients included six with osteoarthritis, two with ankylosing spondylitis, one with Reiter's syndrome and one with post-traumatic effusion.

The effusions were immediately centrifuged at $2500 \mathrm{rev} . / \mathrm{min}$ for 20 minutes at room temperature to remove cellular elements and the cell-free effusions treated with 0.02 $\mathrm{mg}$ of hyaluronidase/ml of joint fluid (bovine testes hyaluronidase, type I, Sigma Chem.

Accepted for publication August 1975. 
Corp., St. Louis, Mo.) for 2 hours at $37^{\circ} \mathrm{C}$. The treated synovial effusions were centrifuged again and then either tested immediately or frozen at $-70^{\circ} \mathrm{C}$ until tested.

Lymphocyte cultures were prepared from heparinized peripheral blood obtained from eight different normal donors utilizing the Ficoll-Hypaque gradient separation procedure (Böyum, 1968). Five to $15 \times 10^{6}$ lymphocytes were cultured in $2 \mathrm{ml}$ of RPMI 1640 medium buffered with Hepes buffer (Gibco, Grand Island, N.Y.) and supplemented with $10 \%$ heat-inactivated fetal calf serum (FCS) and antibiotics (Penicillin $100 \mathrm{u} / \mathrm{ml}$, Streptomycin $100 \mu \mathrm{g} / \mathrm{ml}$ ). Upon addition of prepared synovial fluid, lymphocyte cultures were incubated at $37^{\circ} \mathrm{C}$ in $95 \%$ air $-5 \% \mathrm{CO}_{2}$. After 48 hours, cultures were centrifuged at $800 \mathrm{rev} . / \mathrm{min}$ for 10 minutes and the medium containing all added materials removed and replaced by $2 \mathrm{ml}$ of special minimal essential medium (MEM) (Gibco, Grand Island, N.Y.) lacking four essential amino acids and containing $5 \%$ pooled, heat-inactivated human $\mathrm{AB}$ serum and antibiotics. To each culture, $5 \mu \mathrm{Ci}$ of ${ }^{14} \mathrm{C}$-labelled amino acid mixture (Schwarz-Mann, Orangeburg, N.Y.) was added containing the four amino acids L-arginine (specific activity $312 \mathrm{mCi} / \mathrm{mmol}$ ), L-leucine (s.a. $312 \mathrm{mCi} / \mathrm{mmol}$ ), L-lysine (s.a. $310 \mathrm{mCi} / \mathrm{mmol}$ ) and $\mathrm{L}$-valine (s.a. $258 \mathrm{mCi} / \mathrm{mmol}$ ) missing in the special MEM, each at a concentration of $250 \mu \mathrm{Ci} / \mathrm{ml}$. The cultures were then incubated under the same conditions for another 24-hour period. On termination of culture, all cellular elements were removed by ultracentrifugation at $35000 \mathrm{rev}$./min for 1 hour and the supernatants then dialysed against four changes of $0.01 \mathrm{M}$-phosphate-buffered saline (PBS), pH 7.2.

The determination of the incorporation of ${ }^{14} \mathrm{C}$-amino acids into new synthesized immunoglobulin was performed according to the method of Jasin and Ziff (1969) as modified by Jasin and Ziff (1975). In short, aliquots of $0.1 \mathrm{ml}$ of the supernatants were taken for the determinations of total radioactivity, the TCA-precipitable radioactivity, the radioactivity present in the immune precipitate formed in slight antibody excess with polyvalent goat anti-human immunoglobulin antiserum (Meloy Labs., Springfield, Va.) and in a nonspecific precipitate formed in equivalence by egg albumin-anti-egg albumin. The counts obtained for the nonspecific precipitation represented about $2-5 \%$ of the total counts and were subtracted from the counts obtained for the immune precipitate. The precipitates were counted upon addition of $1 \mathrm{ml}$ of $0.1 \mathrm{M}-\mathrm{NaOH}, 2 \mathrm{ml}$ of saline and $10 \mathrm{ml}$ of Aquasol (New England Nuclear, Boston, Mass.) in a Beckman fluid scintillation counter. Cell viability counts performed at the beginning and in some experiments at the end of the cultures were done utilizing the trypan blue dye exclusion technique.

\section{RESULTS}

The effect of synovial effusions on cell viability counts and protein synthesis of normal lymphocyte cultures

Different peripheral lymphocyte cultures from different normal donors were incubated in the presence of three different concentrations of six rheumatoid and four nonrheumatoid joint effusions. After 72 hours of incubation, cell viability counts using the trypan blue exclusion technique were performed and are given in Fig. 1. It can be seen that three different amounts of either rheumatoid or non-rheumatoid synovial effusions present in the lymphocyte culture did not change the cell viability counts significantly.

Similar findings are observed in the estimation of protein synthesis as measured by the counts of ${ }^{14} \mathrm{C}$ precipitated with $5 \%$ TCA in $0.1 \mathrm{ml}$ of culture supernatant following an extensive dialysis (Fig. 2). The estimated protein synthesis shows no significant change for the different concentration of effusions added, suggesting that not only is viability not jeopardized, but also no toxic effect is exerted upon the lymphocyte cultures. The 
apparent trend toward a decreased incorporation of the ${ }^{14} \mathrm{C}$-label in the TCA precipitate was not present upon examination of the individual lymphocyte cultures.

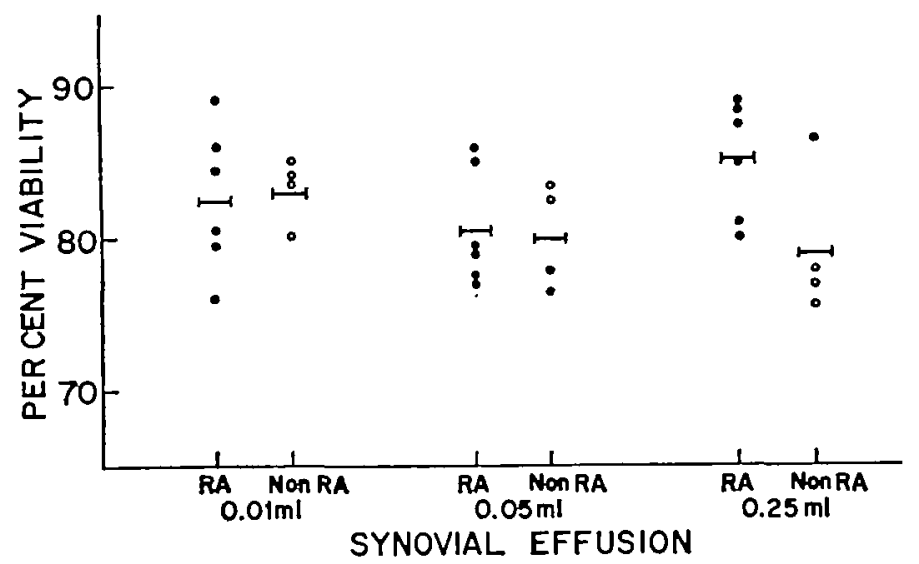

Fig. 1.-Percentage viability at termination of cultures as determined by the trypan blue dye exclusion technique. All determinations were performed in duplicate. There is no significant statistical difference between the values obtained for RA and non-RA synovial effusions containing cultures.

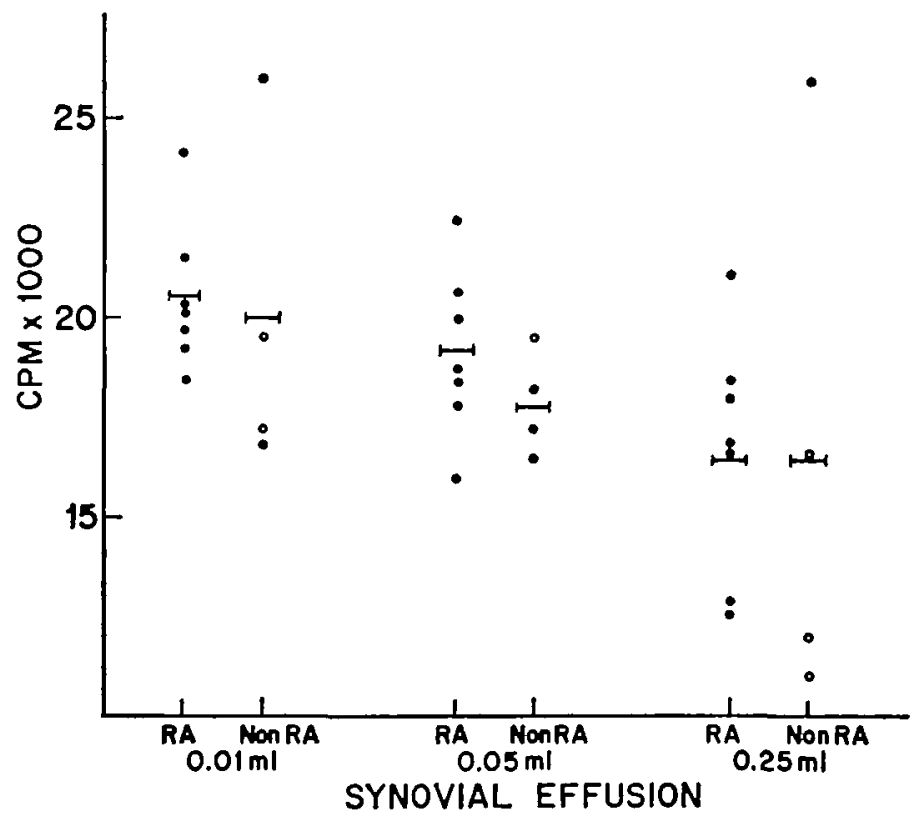

FIG. 2. Counts per minute obtained for the TCA-precipitable material in $0.1 \mathrm{ml}$ of culture supernatant. All determinations were performed in duplicate. There is no significant statistical difference between the values obtained for RA and non-RA synovial effusions containing cultures. 
The effect of different amounts of synovial effusions on immunoglobulin synthesis of normal lymphocyte cultures

Utilizing a radioactive immune coprecipitation assay, immunoglobulin determinations of normal lymphocyte cultures in the presence of different amounts of joint effusions were performed (Table). Immunoglobulin synthesis in the presence of varying amounts

TABLE

The EfFect of Different Amounts of Rheumatoid and Non-RHEumatom Synovial EFfusions on Immunoglobulin Synthesis in Normal Peripheral Blood Lymphocytes

\begin{tabular}{|c|c|c|c|c|}
\hline \multirow{2}{*}{$\begin{array}{l}\text { Amount of } \\
\text { effusion } \\
\text { added }\end{array}$} & \multicolumn{2}{|c|}{ Rheumatoid arthritis ${ }^{1}$} & \multicolumn{2}{|c|}{ Non-rheumatoid arthritis 1} \\
\hline & ct. $/ \min \pm$ s.D..$^{2}$ & S.I. \pm S.D. ${ }^{3}$ & ct. $/ \min \pm$ s.D. ${ }^{2}$ & S.I.土S.D. ${ }^{8}$ \\
\hline $0.25 \mathrm{ml}$ & $\begin{array}{l}597 \pm 97 \\
(P<0.01)\end{array}$ & $\begin{array}{c}0.75 \pm 0.13 \\
(P=0.05)\end{array}$ & $\begin{array}{l}820 \pm 118 \\
\text { (N.S.) }\end{array}$ & $0.88 \pm 0.11$ \\
\hline $0.20 \mathrm{ml}$ & $\begin{array}{l}1190 \pm 489 \\
\text { (N.S.) }\end{array}$ & $\begin{array}{l}1.14 \pm 0.30 \\
(\text { N.S. })\end{array}$ & $\begin{array}{l}920 \pm 55 \\
\text { (N.S.) }\end{array}$ & $1.06 \pm 0.17$ \\
\hline $0.10 \mathrm{ml}$ & $\begin{array}{c}1783 \pm 330 \\
(P<0.01)\end{array}$ & $\begin{array}{c}1.77 \pm 0.17 \\
(P<0.001)\end{array}$ & $\begin{array}{l}827 \pm 147 \\
\text { (N.S.) }\end{array}$ & $0.93 \pm 0.15$ \\
\hline $0.05 \mathrm{ml}$ & $\begin{array}{c}2027 \pm 880 \\
(P<0.01)\end{array}$ & $\begin{array}{c}2.14 \pm 0.88 \\
(P<0.001)\end{array}$ & $\begin{array}{l}852 \pm 79 \\
\text { (N.S.) }\end{array}$ & $0.99 \pm 0.13$ \\
\hline $0.01 \mathrm{ml}$ & $\begin{array}{c}3125 \pm 946 \\
(P<0.01)\end{array}$ & $\begin{array}{c}3.56 \pm 1.17 \\
(P<0.001)\end{array}$ & $\begin{array}{l}1009 \pm 260 \\
\text { (N.S.) }\end{array}$ & $1.20 \pm 0.42$ \\
\hline $0.005 \mathrm{ml}$ & $\begin{array}{c}1962 \pm 879 \\
(P<0.01)\end{array}$ & $\begin{array}{r}1.87 \pm 0.65 \\
(P<0.01)\end{array}$ & $\begin{array}{l}830 \pm 197 \\
\text { (N.S.) }\end{array}$ & $0.95 \pm 0.24$ \\
\hline
\end{tabular}

Medium

$902 \pm 145$

1 Fourteen different hyaluronidase-treated synovial effusions from rheumatoid arthritis patients and 10 synovial effusions from non-rheumatoid patients were assayed on eight different normal lymphocyte donors. The non-rheumatoid fluids were obtained from two patients with ankylosing spondylitis, six with osteoarthritis, one with Reiter's syndrome and one with pasttraumatic effusion. All experiments were performed in duplicate.

${ }^{2}$ Counts per minute per $0.1 \mathrm{ml}$ of culture supernatant. The significance is determined as compared to medium control.

${ }^{8}$ Stimulation Index $=\frac{\mathrm{ct} . / \mathrm{min} \text { experimental culture }}{\mathrm{ct} . / \mathrm{min} \text { medirum control }}$ cultures.

The significance determined between rheumatoid and non-rheumatoid effusions containing

of non-rheumatoid effusion shows no significant changes. However, rheumatoid synovial effusions exert profound effects on the production of immunoglobulins. Low concentrations, such as $0.005 \mathrm{ml}$ added to $2 \mathrm{ml}$ lymphocyte cultures are already actively enhancing. Maximal stimulation is present in cultures to which $0.01 \mathrm{ml}$ of joint effusions was added. Increasing amounts of rheumatoid synovial fluids added to the cultures reduced the stimulatory effect with, eventually, no immunoglobulin synthesis upon addition of 0.25 $\mathrm{ml}$ of synovial fluid. 


\section{DISCUSSION}

The rheumatoid synovium is a playground for multiple immunological and metabolic events resulting in a chronic perpetuative inflammation. Both humoral and cellular immune mechanisms have been shown to be involved in this process (Pekin et al., 1964; Smiley et al., 1968; Winchester et al., 1969; Rodman et al., 1967; Bacon et al., 1973; Waxman et al., 1973; Rothenberger and Thiele, 1970; Clot et al., 1973). It is therefore to be expected that synovial effusions will contain material released during such events. In earlier publications, we have demonstrated that mediators of delayed hypersensitivity can be found in rheumatoid synovial effusions (Stastny et al., 1975) and intra-articular injections of such mediator preparations evoke the development of a chronic synovitis resembling to some extent rheumatoid arthritis (Andreis et al., 1974). In a recent publication we adduced evidence for the presence of factors enhancing the synthesis of immunoglobulins in rheumatoid joint effusions (Rosenthal et al., 1976).

The immune response to certain antigens is controlled not only by a $T$ cell population with enhancing capacity on immunoglobulin synthesis, but also by a subpopulation of $T$ cells with suppressive effect on antibody response. Recent work done by Katz, Paul and Benacerraf (1973) interpreted the observation of inhibition of antibody response as due to release of soluble inhibitory mediators most likely by $T$ lymphocytes. In this communication, evidence was brought that the two antagonistic activities can be demonstrated in synovial fluids produced in vivo. To what extent suppressive or enhancing activities are manifested depends upon the dilution of the synovial effusion while exposed to lymphocyte cultures. The presence of $12.5 \%$ rheumatoid synovial fluids in the lymphocyte cultures inhibits the immunoglobulin synthesis specifically without exerting any detectable toxic effect on the viability or impairment of the protein synthesis in the lymphocytes. Subsequent dilution of the synovial fluid gives rise to extensive production of immunoglobulin reaching an optimum concentration of $0.5 \%$ of synovial effusion present in the lymphocyte cultures. The effect observed here does not seem to be mediated by a specific factor because it can be demonstrated in normal, unsensitized lymphocytes. The question of whether the suppression or stimulation of immunoglobulin synthesis is mediated by the same factor in different concentrations or by two different agents is the subject of further studies.

\section{REFERENCES}

ANDREIS, M., STASTNY, P. and Z ZFF, M. (1974) "Experimental Arthritis Produced by Injection of Mediators of Delayed Hypersensitivity". Arthritis Rheum., 17, 537.

Bacon, P. A., Bluestone, R., Cracciolo, A. and Goldbero, L. S. (1973) "Cell-mediated Immunity to Synovial Antigens in Rheumatoid Arthritis". Lancet ii, 699.

Barer, P. J., Reed, N. D., Stashak, P. W., Amsbaugh, Diana, F. and Prescott, B. (1973) "Regulation of the Antibody Response to Type III Pneumococcal Polysaccharide: I. Nature of Regulatory Cells". J. Exp. Med., 137, 1431 .

Bbyum, A. (1968) "Isolation of Mononuclear Cells and Granulocytes from Human Blood". Scand. J. Clin. Lab. Invest., $21,97$.

CLOT, J., SANY, J. and SERRE, H. (1973) "Cellular Immunity in Rheumatoid Arthritis: I. Study of the Response to Undenatured IgG". Pathologie-Biologie, France, 21, 465.

DutToN, R. W. (1973) "Inhibitory and Stimulatory Effects of Concanavalin A on the Response of Mouse Spleen Cell Suspensions to Antigen: II. Evidence for Separate Stimulatory and Inhibitory Cells".J. Exp. Med., 138, 1496.

Hardin, J. A., Chused, T. M. and SteinberG, A. D. (1973) "Suppressor Cells in the Graft v. Host Reaction". J. Immunol., 111, 650.

Herzenderg, Leonore, A., Chan, Eva, L., Ravitch, Myrnice, M., Riblet, R. J. and HerzenBERG, LeONARD, A. (1973) “Active Suppression of Immunoglobulin Allotype Synthesis: III. Identification of T Cells as Responsible for Suppression by Cells from Spleen, Thymus, Lymph Node and Bone Marrow".J. Exp. Med., 137, 1311. 
JAsIN, H. E. and ZIFF, M. (1969) "Immunoglobulin and Specific Antibody Synthesis in Chronic Inflammatory Focus: Antigen Induced Synovitis". J. Immunol., 102, 355. and - (1975) "Immunoglobulin Synthesis by Peripheral Blood Cells in Systemic Lupus Erythematosus". Arthritis Rheum., 18, 219.

Katz, D. H., Paul, W. E. and Benacerraf, B. (1973) "Carrier Function in Anti-hapten Antibody Responses: VI. Establishment of Experimental Conditions for either Inhibitory or Enhancing Influences of Carrier-specific Cells on Antibody Production". J. Immunol., 110, 107.

PekIN, T. J. and ZvaIFler, N. J. (1964) "Hemolytic Complement in Synovial Fluid". J. Clin. Invest., 43, 1372.

Rodman, W. S., WILliams, R. C., BILKA, P. J. et al. (1967) “Immunofluorescent Localization of the Third and Fourth Component of Complement in Synovial Tissue from Patients with Rheumatoid Arthritis". J. Lab. Clin. Med., 69, 141.

ROPES, M., BenNetT, G. A., COBB, S., JACOX, R. and JesSAR, R. (1959) "Diagnostic Criteria for Rheumatoid Arthritis". Bull. Rheum. Dis., 9, 175.

Rosenthal, M., STASTNY, P. and ZIFF, M. (1976) "Enhancement of Immunoglobulin and Antiimmunoglobulin Synthesis by Fractions of Rheumatoid Synovial Fluid and Synovial Tissue Culture Supernatants". In the press.

Rothengerger, W. and Thiele, H. G. (1970) "In vitro Studien zur Pathogenese der primarchronischen Polyarthritis mittels des Migrations-Inhibitionstests". Klin. Wochenschr. 1308.

SJÖBERG, O. (1972) "Effect of Allogeneic Cell Interaction on the Primary Immune Response in vitro. Cell Types Involved in Suppression and Stimulation of Antibody Synthesis". Clin. Exp. Immunol., 12, 365.

SMILEY, J. D., SACKS, C. and ZIFF, M. (1968) “In vitro Synthesis of Immunoglobulin by Rheumatoid Synovial Membrane". J. Clin. Invest., 47, 664.

Stastivy, P., Rosenthal, M., ANDREIS, M. and ZiFF, M. (1975) "Lymphokines in the Rheumatoid Joint". Arthritis Rheum., 18, 237.

Waxman, J., Lockshin, M. D., Schnapp, J. J. and Doneson, Ira N. (1973) “Cellular Immunity in Rheumatic Disease: I. Rheumatoid Arthritis". Arthritis Rheum., 16, 499.

Winchester, R. J., AGNello, V. and KunKEL, H. (1969) "The Joint Fluid Gamma-globulin Complexes and their Relationship to Intra-articular Complement Diminution". Ann. N.Y. Acad. Sci., 168, 195. 